\title{
Mental techniques to improve performance
}

\author{
Richard Crevenna
}

Published online: 12 May 2016

(C) Springer-Verlag Wien 2016

Dear Reader,

“The winner takes it all!" - In the next few weeks, the UEFA Euro 2016 (European Soccer Championships) will be held in France. The players of every national soccer team dream to be the next European champions, and their coaches and delegates are seeking the way to achieve the best performance and to be successful, which could be also in form of mental toughness.

The use of mental techniques to strengthen mental toughness is well accepted for professional athletes at times of championships [1]. In professional sports competitions, different mental techniques such as progressive muscle relaxation techniques, breathing techniques, autogenic training, hypnosis, biofeedback, and visualization have been shown to be able to improve the mental skills of professional athletes [1, 2]. They are used in sports for recovery, to improve performance, and should also be considered when coordinating the care of athletes after sport-induced trauma (sport-associated injury) $[1,2]$.

In the present issue of the Wiener klinische Wochenschrift, Keilani at al. report that in professional athletes - namely, Austrian and international players involved in team sports (others than soccer) in Austria - mental techniques seem to be well accepted but quite rarely used. The authors emphasize that further research should be done to provide new information about this relevant issue so as to optimize performance and to increase the use of mental tech- niques for strengthening mental toughness in professional sports [2].

Beside professional sports, schools, universities, and workplaces are fields where an improvement in performance level is of vital importance today. We were able to show that biofeedback-assisted mental training seems to be feasible, well-accepted, and effective (concerning attention and concentration) in Austrian elementary school pupils [3]. To our opinion, good stress management could help individuals cope with problems that occur at school (maybe also with first love) and at the workplace. To our opinion, stress management should be learned before the first cardiac event or before a long history of musculoskeletal disorders (chronic low-back pain) - in this way it would be truly preventive. Therefore, mental techniques and stress management skills could have an enormous impact on health and performance not only in sports, but also in education and work.

With respect to these considerations and to the results of the study of Keilani et al. - that mental techniques seem to be very well accepted but are currently very rarely used in professional athletes - we emphasize the need to increase research in this field. Colleagues working in sports medicine, prevention, occupational health, and neighboring fields should be aware that developing mental toughness is a skill that can improve performance in almost every area of life.

Conflict of interest R. Crevenna states that there are no conflicts of interest. 


\section{editorial}

\section{References}

1. Gould D, Maynard I. Psychological preparation for the Olympic Games. J Sports Sci. 2009;27:1393-1408.

2. Keilani M, Hasenöhrl T, Gartner I, Krall C, Fürnhammer J, Cenik F, Crevenna R. Use of mental techniques for competition and recovery in professional athletes. Wien Klin Wochenschr. 2016. doi:10.1007/s00508-016-0969-x.

3. Crevenna R, Krammer C, Keilani M. Feasibility and acceptance of biofeedback-assisted mental training in an Austrian elementary school: a pilot study. Wien Med Wochenschr. 2016;166:179-181. 